\title{
Application of a bacterial two-hybrid system for the analysis of protein-protein interactions between FemABX family proteins
}

\author{
Rohrer, Susanne ; Berger-Bächi, Brigitte
}

\begin{abstract}
Protein-protein interactions play an important role in all cellular processes. The development of two-hybrid systems in yeast and bacteria allows for in vivo assessment of such interactions. Using a recently developed bacterial two-hybrid system, the interactions of the Staphylococcus aureus proteins FemA, FemB and FmhB, members of the FemABX protein family, which is involved in peptidoglycan biosynthesis and beta-lactam resistance of numerous Gram-positive bacteria, were analysed. While FmhB is involved in the addition of glycine 1 of the pentaglycine interpeptide of S. aureus peptidoglycan, FemA and FemB are specific for glycines $2 / 3$ and $4 / 5$, respectively. FemA-FemA, FemA-FemB and FemB-FemB interactions were found, while $\mathrm{FmhB}$ exists solely as a monomer. Interactions detected by the bacterial two-hybrid system were confirmed using the glutathione S-transferase-pulldown assay and gel filtration.
\end{abstract}

DOI: https://doi.org/10.1099/mic.0.26315-0

Posted at the Zurich Open Repository and Archive, University of Zurich

ZORA URL: https://doi.org/10.5167/uzh-61925

Journal Article

Published Version

Originally published at:

Rohrer, Susanne; Berger-Bächi, Brigitte (2003). Application of a bacterial two-hybrid system for the analysis of protein-protein interactions between FemABX family proteins. Microbiology, 149(10):27332738 .

DOI: https://doi.org/10.1099/mic.0.26315-0 


\begin{abstract}
Application of a bacterial two-hybrid system for the analysis of protein-protein interactions between FemABX family proteins

Correspondence

Brigitte Berger-Bächi

bberger@immv.unizh.ch

Received 21 February 2003

Revised 2 May 2003

Accepted 5 May 2003

\section{Susanne Rohrer and Brigitte Berger-Bächi}

\author{
University of Zürich, Institute of Medical Microbiology, Gloriastr. 32, CH-8028 Zürich, \\ Switzerland
}

Protein-protein interactions play an important role in all cellular processes. The development of two-hybrid systems in yeast and bacteria allows for in vivo assessment of such interactions. Using a recently developed bacterial two-hybrid system, the interactions of the Staphylococcus aureus proteins FemA, FemB and FmhB, members of the FemABX protein family, which is involved in peptidoglycan biosynthesis and $\beta$-lactam resistance of numerous Gram-positive bacteria, were analysed. While FmhB is involved in the addition of glycine 1 of the pentaglycine interpeptide of $S$. aureus peptidoglycan, FemA and FemB are specific for glycines $2 / 3$ and $4 / 5$, respectively. FemA-FemA, FemA-FemB and FemB-FemB interactions were found, while FmhB exists solely as a monomer. Interactions detected by the bacterial two-hybrid system were confirmed using the glutathione $S$-transferase-pulldown assay and gel filtration.
\end{abstract}

\section{INTRODUCTION}

Protein-protein interactions play an important role in virtually all cellular processes. The yeast two-hybrid (YTH) system has become a widely used tool for determining such interactions in vivo [for review, see Phizicky \& Fields (1995)]. With the complete sequencing of many prokaryotic and eukaryotic genomes, it has even become possible to develop proteome-wide interaction maps using high-throughput YTH systems. In prokaryotes, this has so far been done for Helicobacter pylori (Rain et al., 2001). In Staphylococcus aureus, interactions between FtsA and FtsZ have been analysed using the conventional YTH system (Yan et al., 2000, 2001), as have interactions between MecI and BlaI (McKinney et al., 2001).

With the development of bacterial two-hybrid (BTH) systems (Dove et al., 1997; Karimova et al., 1998), bacterial proteins can now be assayed for interaction under conditions that match their native environment more closely. In the system developed by Karimova et al. (1998) (Fig. 1), the interaction of two proteins fused to Bordetella pertussis adenylate cyclase domains leads to its functional reconstitution and activation of subordinate metabolic pathways, allowing growth on minimal media or assaying for colour formation on MacConkey agar. This BTH system circumvents some of the limitations of the conventional YTH system, in which proteins localized in membranes and transcription factors, for example, are not amenable for

Abbreviations: BTH, bacterial two-hybrid; GST, glutathione S-transferase; His, hexahistidine; HRP, horseradish peroxidase. analysis. In addition, the spatial separation of the interaction event and the signal readout reduces problems arising from non-specific interactions (Karimova et al., 1998).

To validate the BTH system for use with $S$. aureus proteins, we have screened for interactions between FemA, FemB and $\mathrm{FmhB}$, members of the FemABX family of peptidyl transferases that is centrally involved in $\beta$-lactam resistance

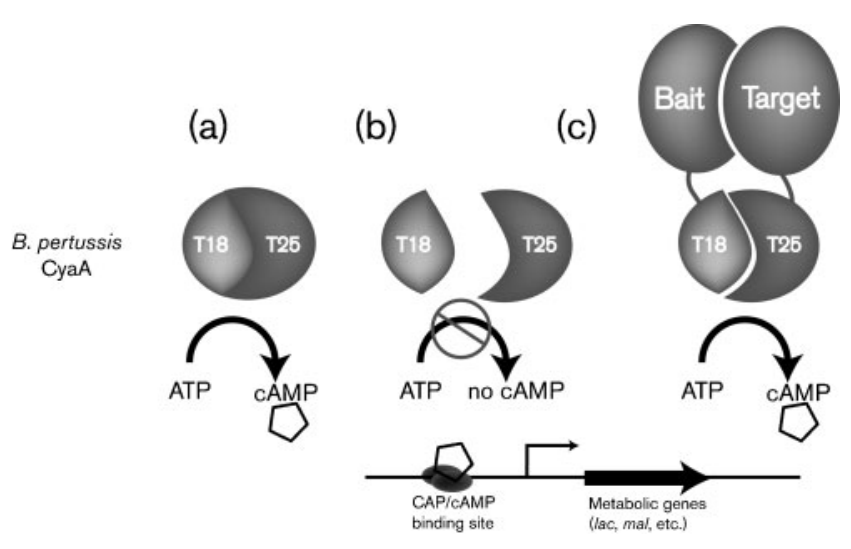

Fig. 1. BTH system (adapted from Karimova et al., 1998). The $B$. pertussis CyaA protein consists of two functional domains, T18 (amino acids 1-224) and T25 (amino acids 225-399) (a). As the protein is split into its domains, it is no longer able to synthesize cAMP (b). Brought into spatial proximity by interaction of a 'bait' and 'target' protein, cAMP synthesis is enabled (c), activating CAP (catabolite activator protein)/cAMP-dependent metabolic genes such as the lac and mal operons. 
and the formation of branched muropeptides in a number of Gram-positive organisms. In S. aureus, these genetic factors have a dramatic impact on viability and resistance to methicillin and other antimicrobial substances (reviewed by Rohrer \& Berger-Bächi, 2003).

We show here that homodimerization occurs for FemA and $\mathrm{FemB}$, but not for $\mathrm{FmhB}$, and that an interaction also occurs between FemA and FemB. The findings of the BTH screen were confirmed using two independent methods, namely, analytical gel filtration and the glutathione $S$-transferase (GST)-pulldown assay.

\section{METHODS}

Plasmid construction. Strains and plasmids used in this work are listed in Table 1. Molecular biology manipulations were done following standard procedures (Ausubel et al., 1997). The 'bait'/ 'prey' vectors pKT25 and pUT18C, the control plasmids pKT25-zip and pUT18C-zip, and the reporter strain Escherichia coli DHM1 were a kind gift of D. Ladant (Institut Pasteur, France). femA, femB and $f m h B$ were amplified from $S$. aureus BB255 genomic DNA by PCR and fused in-frame to the $3^{\prime}$ end of the cyaA gene fragments in plasmids pKT25 and pUT18C, respectively. C-terminal hexahistidine

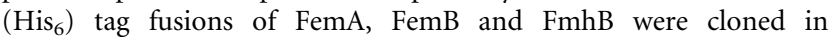
pET24b (Novagen). N-terminal GST fusions of FemA and FemB were cloned in pGEX-2T (Amersham Biosciences). PCR primers used are listed in Table 2.

Screening procedure. All combinations of the constructs were cotransformed into the reporter strain E. coli DHM1 (cya) on LuriaBertani agar containing $100 \mathrm{mg}$ ampicillin $\mathrm{l}^{-1}$ and $20 \mathrm{mg}$ kanamy$\operatorname{cin} 1^{-1}$. Positive controls (provided by D. Ladant) were GCN4 leucine zipper motifs cloned into pKT25 and pUT18C. Negative controls were the empty 'bait' and 'prey' vectors pKT25 and pUT18C. The cotransformants were spotted onto MacConkey agar containing $100 \mathrm{mg}$ ampicillin $\mathrm{1}^{-1}$ and $20 \mathrm{mg}$ kanamycin $\mathrm{1}^{-1}$, and incubated at $30^{\circ} \mathrm{C}$ for 2-3 days. Several colonies of each cotransformation were spotted to exclude clone-by-clone variation. Alternatively, clones were streaked onto M63 minimal agar containing ampicillin and kanamycin, and lactose as the sole carbon source. M63 agar was prepared using $15 \mathrm{~g}$ Bacto Agar $\mathrm{l}^{-1}$ (Difco), $2 \mathrm{~g}\left(\mathrm{NH}_{4}\right)_{2} \mathrm{SO}_{4} \mathrm{l}^{-1}$, $13.6 \mathrm{~g} \mathrm{KH}_{2} \mathrm{PO}_{4} \mathrm{l}^{-1}, 0.5 \mathrm{mg} \mathrm{FeSO}_{4} .7 \mathrm{H}_{2} \mathrm{O} \mathrm{l}^{-1}$, adjusted to $\mathrm{pH} 7 \cdot 0$ with $\mathrm{KOH}$. After autoclaving, $1 \mathrm{ml}$ of $1 \mathrm{M} \mathrm{MgSO}_{4} \cdot 7 \mathrm{H}_{2} \mathrm{O}, 15 \mathrm{ml}$ of $20 \%(\mathrm{w} / \mathrm{v})$ lactose and $2 \mathrm{ml}$ of $0.05 \%(\mathrm{w} / \mathrm{v})$ thiamin (all filtersterilized) were added.

Production of recombinant protein. $\mathrm{His}_{6}$-tagged protein was expressed in E. coli BL21(DE3) cells at $30^{\circ} \mathrm{C}$ induced with $0.5 \mathrm{mM}$ IPTG. Cells were lysed in $1 / 25$ of the original culture volume of lysis buffer $(50 \mathrm{mM}$ sodium phosphate $\mathrm{pH} 8 \cdot 0 / 150 \mathrm{mM} \mathrm{NaCl} / 10 \mathrm{mM}$ imidazole $/ 1 \mathrm{mg}$ lysozyme $\mathrm{ml}^{-1} / 0 \cdot 1 \mathrm{mg}$ DNase $\mathrm{ml}^{-1} / 0 \cdot 01 \mathrm{mg}$ RNase $\mathrm{ml}^{-1} / 0 \cdot 1 \mathrm{mM}$ PMSF) on ice for $30 \mathrm{~min}$. The lysates were then sonicated and centrifuged at $20000 \mathrm{~g}$ for $20 \mathrm{~min}$.

Cleared lysates were incubated with $1 / 20$ volume of Ni-NTAagarose (Qiagen) for $1 \mathrm{~h}$, on an overhead shaker, at $4{ }^{\circ} \mathrm{C}$. The resin was washed with $10-15$ volumes of wash buffer $(50 \mathrm{mM}$ sodium phosphate $\mathrm{pH} 8 \cdot 0 / 150 \mathrm{mM} \mathrm{NaCl} / 10 \mathrm{mM}$ imidazole). Protein was eluted with 3-4 column volumes of elution buffer $(50 \mathrm{mM}$ sodium phosphate $\mathrm{pH} 8 \cdot 0 / 100 \mathrm{mM} \mathrm{NaCl} / 200 \mathrm{mM}$ imidazole). The eluates were centrifuged in Centricon centrifugal filter devices (Millipore)

Table 1. Strains and plasmids used in this work

\begin{tabular}{|c|c|c|}
\hline Strain/plasmid & Genotype/description ${ }^{\star}$ & Origin/reference \\
\hline \multicolumn{3}{|l|}{ Strain } \\
\hline S. aureus BB255 & Essentially as for NCTC 8325 ; template for PCR & Berger-Bächi (1983) \\
\hline E. coli $\mathrm{DH} 5 \alpha$ & Cloning strain & Invitrogen \\
\hline E. coli $\mathrm{BL} 21(\mathrm{DE} 3)$ & Expression strain & Novagen \\
\hline E. coli DHM1 & Reporter strain for BTH system; cya & D. Ladant; Karimova et al. (1998) \\
\hline \multicolumn{3}{|l|}{ Plasmid } \\
\hline pKT25 & Two-hybrid plasmid, cyaAT25 fusion; $\operatorname{Kan}^{\mathrm{r}}$ & D. Ladant; Karimova et al. (1998) \\
\hline pUT18C & Two-hybrid plasmid, cyaAT18 fusion; $\mathrm{Amp}^{\mathrm{r}}$ & D. Ladant; Karimova et al. (1998) \\
\hline pKT25-zip & Two-hybrid control plasmid & D. Ladant \\
\hline pUT18C-zip & Two-hybrid control plasmid & D. Ladant \\
\hline pET24b & Expression plasmid for $\mathrm{His}_{6}$ fusions; $\mathrm{Kan}^{\mathrm{r}}$ & Novagen \\
\hline pGEX-2T & Expression plasmid for GST fusions; $A p^{r}$ & Amersham Biosciences \\
\hline pKT25fmhB & Two-hybrid plasmid containing $c y a A T 25-f m h B$ fusion & This work \\
\hline pKT25femA & Two-hybrid plasmid containing cyaAT25-femA fusion & This work \\
\hline pKT25femB & Two-hybrid plasmid containing cyaAT25-femB fusion & This work \\
\hline pUT18CfmhB & Two-hybrid plasmid containing $c y a A T 18-f m h B$ fusion & This work \\
\hline pUT18CfemA & Two-hybrid plasmid containing cyaAT18-femA fusion & This work \\
\hline pUT18CfemB & Two-hybrid plasmid containing cyaAT18-femB fusion & This work \\
\hline pET24bfmhB & Expression plasmid to produce $\mathrm{FmhB}$ with $\mathrm{His}_{6}$ fused to $\mathrm{C}$ terminus & This work \\
\hline pET24bfemA & Expression plasmid to produce FemA with $\mathrm{His}_{6}$ fused to $\mathrm{C}$ terminus & This work \\
\hline pET24bfemB & Expression plasmid to produce FemB with $\mathrm{His}_{6}$ fused to $\mathrm{C}$ terminus & This work \\
\hline pGEX2TfemA & Expression plasmid to produce FemA with GST fused to $\mathrm{N}$ terminus & This work \\
\hline pGEX2TfemB & Expression plasmid to produce FemB with GST fused to $\mathrm{N}$ terminus & This work \\
\hline
\end{tabular}

${ }^{\star} \mathrm{Kan}^{\mathrm{r}}$, kanamycin-resistant; Amp ${ }^{\mathrm{r}}$, ampicillin-resistant. 
Table 2. Oligonucleotides used in this work

\begin{tabular}{|c|c|c|}
\hline Primer designation & Oligonucleotide sequence & Restriction site \\
\hline femA BTH pKT25 fwd & GAACTGCAGTGAAGTTTACAAATTTAACAG & Pst $\mathrm{I}$ \\
\hline femA BTH pUT18C fwd & GATCTGCAGGAAGTTTACAAATTTAACAG & Pst $\mathrm{I}$ \\
\hline femA BTH rev & GCAGGTACCCTAAAAAATTCTGTCTTTAAC & KpnI \\
\hline femB BTH pUT18C fwd & GCA $\overline{\overline{C T G C A G G A A A T T T A C A G A G T T A A C T G ~}}$ & Pst $\mathrm{I}$ \\
\hline femB BTH pKT25 fwd & GCACTGCAGTGAAATTTACAGAGTTAACTG & Pst I \\
\hline femB BTH rev & GCAGGTACCTTAATTTTTTACGTAATTTATC & $K p n \mathrm{I}$ \\
\hline$f m h B$ BTH pUT18C fwd & CTACTGCAGGGAAAAGATGCATATCAC & Pst $\mathrm{I}$ \\
\hline$f m h B$ BTH pKT25 fwd & CATCTGCAGTGGAAAAGATGCATATCAC & Pst $\mathrm{I}$ \\
\hline $\mathrm{fmhB}$ BTH rev & GCAGGTACCTATTTTCGTTTTAATTTACG & KpnI \\
\hline$f m h B$ pET24b fwd & CGA $\overline{\text { GCTAGCGAAAAGATGCATATCACTAATC }}$ & NheI \\
\hline$f m h B$ pET24b rev & GCACTCGAGTTTTCGTTTTAATTTACG & XhoI \\
\hline femA pET24b fwd & 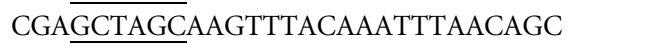 & NheI \\
\hline femA pET24b rev & GCACTCGAGAAAAATTCTGTCTTTAAC & XhoI \\
\hline femB pET24b fwd & CGAGCTAGCAAATTTACAGAGTTAACTGTTAC & NheI \\
\hline femB pET24b rev & GCACTCGAGTTTCTTTAATTTTTTACTAATTTATC & XhoI \\
\hline femA pGEX fwd & GTTGGATCCAAGTTTACAAATTTAACAGCTA & BamHI \\
\hline femA pGEX rev & GTTGAATTCCTAAAAAATTCTGTCTTTAACTTT & EcoRI \\
\hline femB pGEX fwd & CAAGGATCCAAATTTACAGAGTTAACTGTTAC & BamHI \\
\hline femB pGEX rev & GTTGAATTCTTTAATTTTTTACGTAATTTATCC & EcoRI \\
\hline
\end{tabular}

with a cut-off of $10 \mathrm{kDa}$ to exchange the buffer for PBS $(8.5 \mathrm{~g}$ $\left.\mathrm{NaCl} \mathrm{l} l^{-1}, 10 \cdot 7 \mathrm{~g} \mathrm{Na}_{2} \mathrm{HPO}_{4} \cdot 2 \mathrm{H}_{2} \mathrm{O} \mathrm{l}^{-1}, 0 \cdot 9 \mathrm{~g} \mathrm{KH}_{2} \mathrm{PO}_{4} \mathrm{l}^{-1}, \mathrm{pH} 7 \cdot 4\right)$. The recombinant protein was more than $95 \%$ pure on SDS-PAGE and Coomassie staining (not shown).

GST fusions of FemA and FemB were purified similarly. The fusion proteins were expressed in E. coli BL21(DE3) cells with $0.05 \mathrm{mM}$ IPTG at $17^{\circ} \mathrm{C}$ for $1 \mathrm{~h}$. Cells were lysed in $1 / 25$ of the original culture volume of lysis buffer as above, with addition of $1 \%(\mathrm{v} / \mathrm{v})$ Triton $\mathrm{X}-100$, omitting imidazole. Cleared lysates were bound to $1 / 40$ to $1 / 20$ volume of glutathione-agarose (Sigma) at $4{ }^{\circ} \mathrm{C}$ for $1 \mathrm{~h}$, on an overhead shaker, washed with 20 volumes of PBS and eluted with $50 \mathrm{mM}$ Tris/ $\mathrm{HCl} \mathrm{pH} 8 / 150 \mathrm{mM} \mathrm{NaCl} / 5 \mathrm{mM}$ GSH. The protein was more than $95 \%$ pure on SDS-PAGE and Coomassie staining (not shown).

Analytical gel filtration. Protein oligomerization was observed by analytical gel filtration using FPLC on a Superdex 200 HR column on an Äkta FPLC system (Pharmacia). Proteins were run in PBS. In addition to recombinant $\mathrm{His}_{6}$-tagged proteins, a set of protein standards were run (HMW and LMW protein standards; Pharmacia). Peak data of the standards were used to perform linear regression analysis, in order to obtain a standard curve for molecular mass determination of the analysed proteins.

GST-pulldown assay. Cleared lysates of GST-FemA or GST-FemB fusions, or GST alone, were incubated with equal volumes of GSHagarose beads for $1 \mathrm{~h}$ at $4{ }^{\circ} \mathrm{C}$. The bead material was washed with 20 volumes of PBS. Non-specific protein binding was blocked by incubating the bead material for $1 \mathrm{~h}$ with BSA $\left(1 \mathrm{mg} \mathrm{ml}^{-1}\right)$ in PBS at $4{ }^{\circ} \mathrm{C}$. The material was again washed with 20 volumes of PBS. His $_{6}$-tagged FemA or FemB protein was added in excess and incubated with the bead-bound proteins for $2 \mathrm{~h}$ at $4{ }^{\circ} \mathrm{C}$. Unbound protein was removed by washing three times with 10 volumes of PBS, and the bead samples with bound protein were suspended in equal volumes of SDS sample buffer.

Western blotting. SDS-PAGE and Western blotting were done following standard procedures (Ausubel et al., 1997). Western blots were incubated with monoclonal anti-His antibody (Sigma) at
1:1000 dilution in PBS containing $0.03 \%(w / v)$ Top Block (Juro) overnight at $4{ }^{\circ} \mathrm{C}$, followed by secondary antibody (Sheep antimouse $\mathrm{F}_{\mathrm{ab}}-\mathrm{HRP}$; Jackson Immuno Research) at 1:10000 dilution for $2 \mathrm{~h}$ at room temperature $\left(22^{\circ} \mathrm{C}\right)$. Detection was done with SuperSignal West Femto reagent (Pierce).

\section{RESULTS}

\section{BTH screening}

$f m h B, f e m A$ and $f e m B$ were each cloned into the 'bait' and 'prey' vectors and all nine combinations were cotransformed into the reporter strain DHM1. Cotransformants were streaked onto MacConkey or M63 minimal agar plates containing lactose as the sole carbon source. After 2-3 days incubation at $30^{\circ} \mathrm{C}$, colour formation was observed for interactors on MacConkey agar, while non-interactors remained white (Fig. 2). The positive controls, two leucinezipper domains, gave rise to stronger colour formation, which was assumed to be due to very strong interaction between these proteins. On minimal agar, positive clones grew after 3-4 days (not shown).

Positive clones were obtained for the combinations pUT18CfemA/pKT25femA, pUT18CfemA/pKT25femB, pUT18CfemB/pKT25femA and pUT18CfemB/pKT25femB, while all combinations with $f m h B$ were negative. We therefore assumed an interaction for the positive combinations and proceeded to confirm these interactions using independent methods.

\section{Analytical gel filtration}

His $_{6}$-tagged protein was run on a Superdex $200 \mathrm{HR}$ size exclusion column to determine protein oligomerization. 


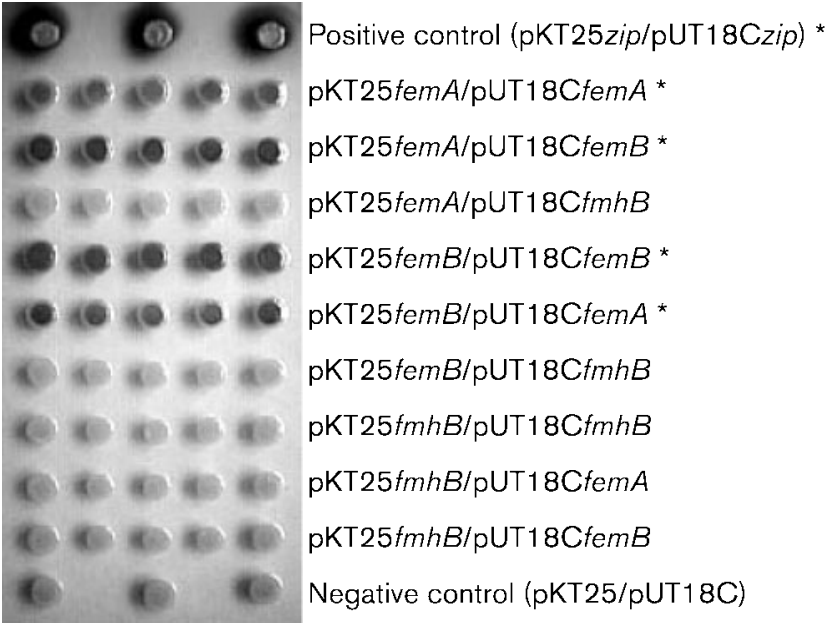

Fig. 2. Growth of FemAB/FmhB BTH cotransformants on MacConkey agar. Several clones of each 'bait'/"prey' plasmid cotransformation were spotted, along with positive and negative controls. lac-positive clones (interactors) show colour formation $\left.{ }^{*}\right)$, while non-interactors remain white. Due to a very strong interaction, the positive control gives a strong signal.

A standard curve was derived by running protein standards under the same conditions and performing linear regression analysis on the peak data. From this standard curve, the peak sizes of the recombinant proteins could be determined. For the monomers of FmhB, FemA and FemB, the measured molecular masses correlated well with the theoretical values derived from the amino acid sequences, and it was determined that FemA and FemB formed dimers (Fig. 3a, b; Table 3).

\section{GST-pulldown assay}

Since by analytical gel filtration a FemA/FemB heterodimer was not expected to be distinguishable from their homodimers, GST-pulldown assays were done. FemA and FemB were expressed as GST fusions. To control for non-specific binding, GST alone was used. GST, GST-FemA or GSTFemB fusions bound to GSH-agarose were incubated with equal amounts of $\mathrm{His}_{6}$-tagged FemA or FemB, respectively. After washing, bound protein was analysed by Western blotting using an anti-His ${ }_{6}$ antibody (Fig. 3c). While a limited extent of non-specific binding to GST or GSHagarose was observed for FemB, significant specific binding to GST-FemA and GST-FemB, respectively, was observed for both FemA and FemB, confirming their homo- and heterodimerization in vitro that had been observed in the BTH system.

\section{DISCUSSION}

We have demonstrated here that the BTH system developed by Karimova et al. (1998) can be applied to the analysis of
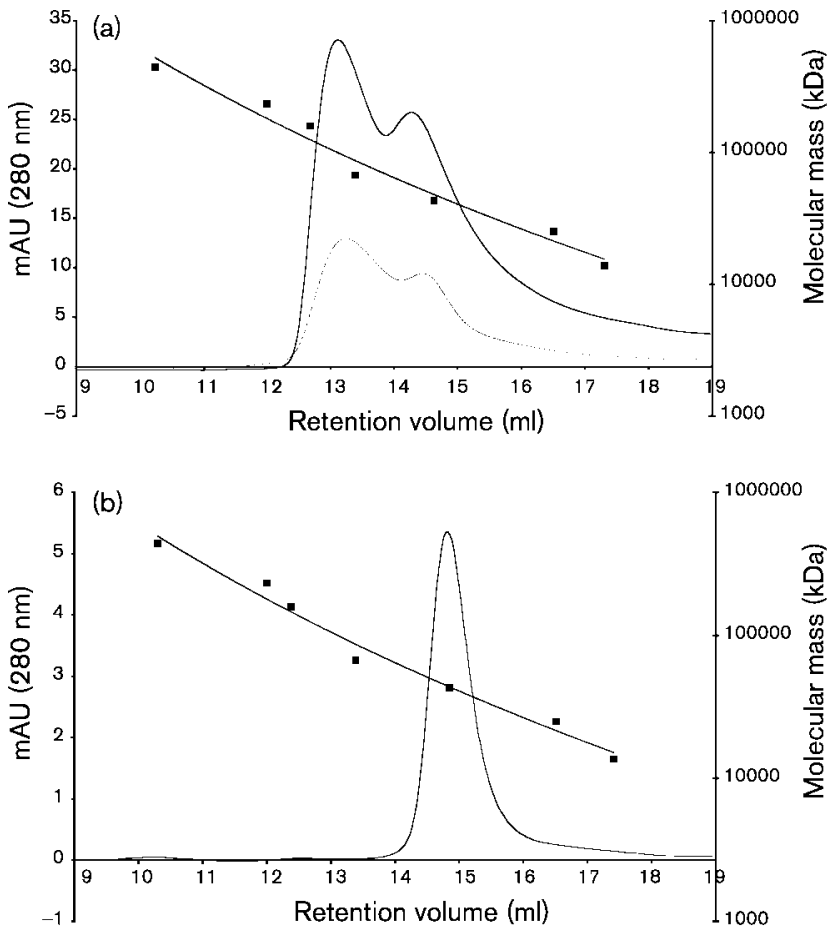

(c)

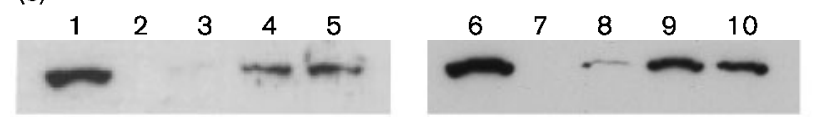

Fig. 3. Analytical gel filtration and GST-pulldown. (a) Gel filtration of FemA (thin line) and FemB (thick line); (b) gel filtration of FmhB. Standard curves were calculated using linear regression analysis. Peak sizes are listed in Table 3. mAU, Milliabsorbance units. (c) GST-pulldown assay analysed by Western blot. Equal amounts of sample were loaded. $\mathrm{His}_{6}$-tagged protein was detected using monoclonal anti-His ${ }_{6}$ antibody (Sigma) at $1: 1000$ dilution, followed by secondary antibody (Sheep antimouse $\mathrm{F}_{\mathrm{ab}}-\mathrm{HRP}$; Jackson Immuno Research) at 1:10000 dilution. Lanes: 1, $\mathrm{His}_{6}-$ FemA (reference lane); 2, blank; 3, GST control protein $+\mathrm{His}_{6}-\mathrm{FemA} ; 4$, GST-FemA + $\mathrm{His}_{6}-\mathrm{FemA}$; 5, GST-FemB $+\mathrm{His}_{6}-\mathrm{FemA} ; 6, \mathrm{His}_{6}-\mathrm{FemB}$ (reference lane); 7, blank; 8, GST control+His ${ }_{6}-\mathrm{FemB} ; 9$, GST-FemA+His 6 FemB; 10, GST-FemB + His $_{6}-$ FemB.

staphylococcal proteins, by showing interaction of FemAFemA, FemA-FemB and FemB-FemB. Although the interacting clones were always negative in combination with $\mathrm{FmhB}$, which excluded a false-positive result, any interactions found in a two-hybrid assay have to be validated carefully using independent methods to rule out false-positives. Analytical gel filtration allowed us to confirm homodimerization of FemA and FemB, and demonstrated that FmhB is very likely a monomer in vivo, but we cannot rule out protein-protein interaction(s) mediated by some auxiliary molecule in Staphylococcus. The GSTpulldown assay was done to confirm unanimously all interactions found in the BTH screen. 
Table 3. Molecular masses of FmhB, FemA and FemB as measured by gel filtration

\begin{tabular}{|lccc|}
\hline Protein & $\begin{array}{c}\text { Theoretical molecular } \\
\text { mass }(\mathbf{k D a})\end{array}$ & $\begin{array}{c}\text { Measured molecular } \\
\text { mass }(\mathbf{k D a})\end{array}$ & $\begin{array}{c}\text { Measured dimer } \\
\text { molecular mass }(\mathbf{k D a})\end{array}$ \\
\hline FmhB & $48 \cdot 5$ & $50 \cdot 0$ & $\mathrm{NA}$ \\
FemA & $49 \cdot 1$ & $49 \cdot 4$ & $89 \cdot 3$ \\
FemB & $49 \cdot 6$ & $53 \cdot 8$ & $95 \cdot 4$ \\
\hline
\end{tabular}

NA, Not applicable.

Additional BTH experiments were done using other members of the FemABX family. The lysostaphin immunity factor Lif protects Staphylococcus simulans biovar staphylolyticus from the action of lysostaphin and has been shown to substitute serine in positions 3 and 5 of the pentaglycine side chain in $S$. aureus, in cooperation with FemA and FemB (Ehlert et al., 2000; Thumm \& Götz, 1997). We observed interactions between Lif and both FemA and FemB, but not with FmhB, nor Lif homodimerization (data not shown). Streptococcus pneumoniae FibB (MurN) adds alanine or serine to the stem peptide in cooperation with FibA (MurM) to form an $\mathrm{Ala}_{2}$ or Ala-Ser side chain (Filipe \& Tomasz, 2000; Weber et al., 2000). FibB proved to be able to form homodimers, but not heterodimers with FibA, and FibA homodimerization was also not observed (data not shown). To bring these additional findings into perspective, the sequences of known FemABX family proteins were compared (Fig. 4). It appears that all proteins able to form dimers group in one of two main clades of the family. The non-interactors are grouped in the other,

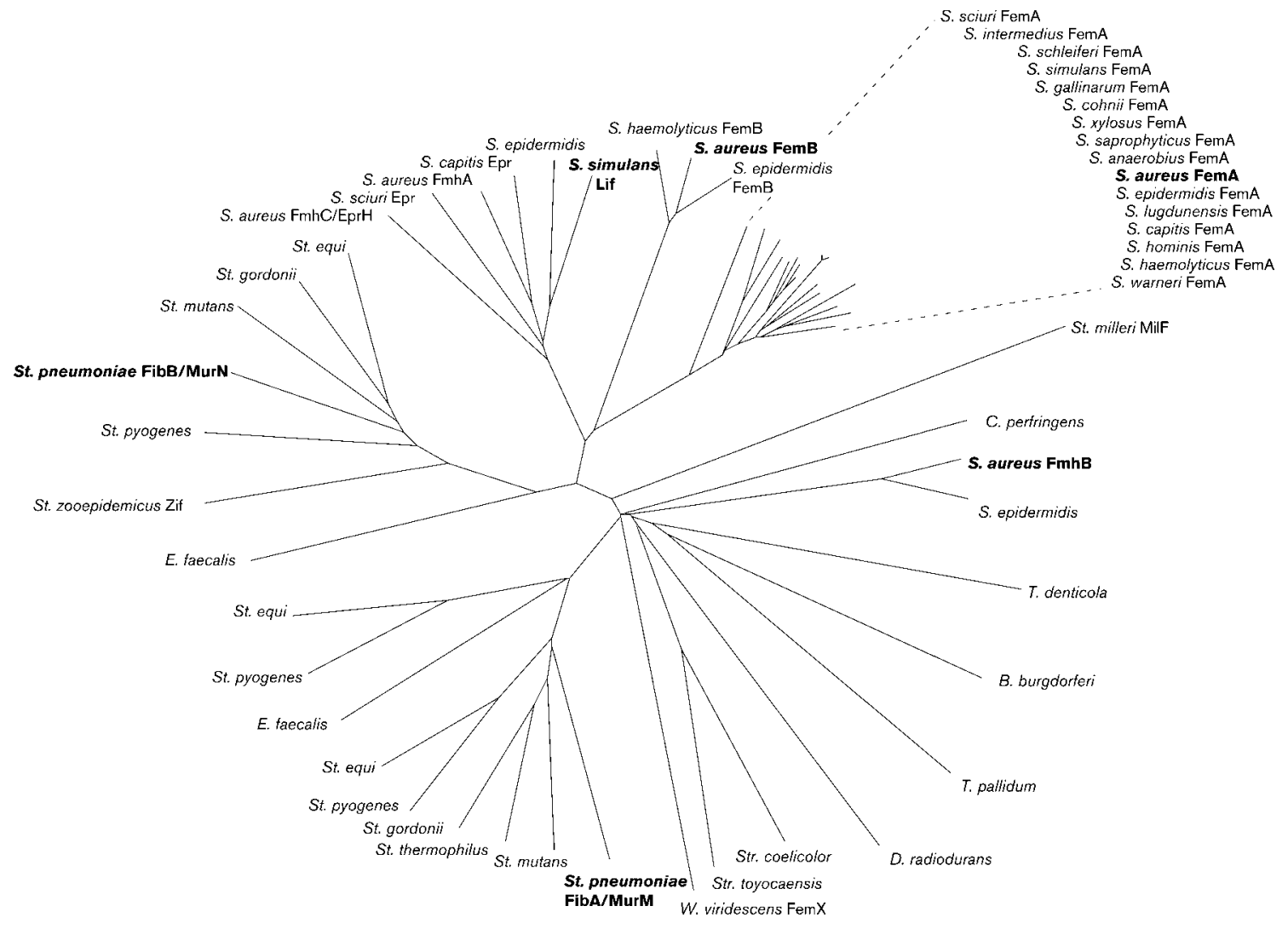

Fig. 4. Dendrogram of the FemABX protein family adapted from Rohrer \& Berger-Bächi (2003). Protein sequences were aligned using CLUSTAL W (Thompson et al., 1994) and the dendrogram was constructed using TREEVIEW (Page, 1996). The labels of the numerous FemA homologues of staphylococci were enlarged, for ease of view. S., Staphylococcus; St., Streptococcus; C., Clostridium; T., Treponema; B., Borrelia; D., Deinococcus; Str., Streptomyces; W., Weissella; E., Enterococcus; S. anaerobius, S. aureus subsp. anaerobius; St. zooepidemicus, St. equi subsp. zooepidemicus. 
evolutionarily older, branch comprising those FemABX family members that add the first amino acid in an interpeptide to the peptidoglycan, and/or are the only family member in the respective species. This may indicate that a gain of function occurred during the diversification of the FemABX protein family. However, this hypothesis would require further experimental testing. Analysis of proteinprotein interactions within the FemABX protein family may yield evidence concerning their function. While there must be a mechanism that determines whether one or two amino acids are attached by a FemABX protein, the data presented here do not imply that interaction or non-interaction contribute to this mechanism.

The protein-protein interactions we were able to show add to the more-detailed knowledge about the FemABX protein family that has been gained in recent years (Benson et al., 2002; Bouhss et al., 2002; reviewed by Rohrer \& BergerBächi, 2003). Proteins of the FemABX family are a recognized target for the development of novel antimicrobial agents (Kopp et al., 1996). It is therefore crucial to understand all aspects of their function in order to advance towards the development of new medicines.

\section{ACKNOWLEDGEMENTS}

The components of the BTH system were a gift of D. Ladant (Institut Pasteur, France). We would like to thank D. Auerbach (Dualsystems Biotech AG, Zürich) for helpful suggestions, and M. Tschierske for cloning femA into pET24b. S. pneumoniae R6 DNA was a kind gift of R. Hakenbeck (Karlsruhe, Germany). Preliminary sequence data from unfinished genomes were obtained from The Institute for Genomic Research and the Sanger Centre. This work was supported by Swiss National Science Foundation grant no. 32-63552.00 to B. B.-B and a grant from the Roche Research Foundation to S. R.

\section{REFERENCES}

Ausubel, F. M., Brent, R., Kingston, R. E., Moore, D. D., Seidman, J. G., Smith, J. A. \& Struhl, K. (1997). Current Protocols in Molecular Biology. New York: Wiley-Interscience \& Greene Publishing Associates.

Benson, T. E., Prince, D. B., Mutchler, V. T., Curry, K. A., Ho, A. M., Sarver, R. W., Hagadorn, J. C., Choi, G. H. \& Garlick, R. L. (2002). $\mathrm{X}$-ray crystal structure of Staphylococcus aureus FemA. Structure 10, 1107-1115.

Berger-Bächi, B. (1983). Insertional inactivation of staphylococcal methicillin resistance by Tn551. J Bacteriol 154, 479-487.

Bouhss, A., Josseaume, N., Severin, A., Tabei, K., Hugonnet, J. E., Shlaes, D., Mengin-Lecreulx, D., van Heijenoort, J. \& Arthur, M.
(2002). Synthesis of the L-alanyl-L-alanine cross-bridge of Enterococcus faecalis peptidoglycan. J Biol Chem 277, 45935-45941.

Dove, S. L., Joung, J. K. \& Hochschild, A. (1997). Activation of prokaryotic transcription through arbitrary protein-protein contacts. Nature 386, 627-630.

Ehlert, K., Tschierske, M., Mori, C., Schröder, W. \& Berger-Bächi, B. (2000). Site-specific serine incorporation by Lif and Epr into positions 3 and 5 of the staphylococcal peptidoglycan interpeptide bridge. J Bacteriol 182, 2635-2638.

Filipe, S. R. \& Tomasz, A. (2000). Inhibition of the expression of penicillin resistance in Streptococcus pneumoniae by inactivation of cell wall muropeptide branching genes. Proc Natl Acad Sci U S A 97, 4891-4896.

Karimova, G., Pidoux, J., Ullmann, A. \& Ladant, D. (1998). A bacterial two-hybrid system based on a reconstituted signal transduction pathway. Proc Natl Acad Sci U S A 95, 5752-5756.

Kopp, U., Roos, M., Wecke, J. \& Labischinski, H. (1996). Staphylococcal peptidoglycan interpeptide bridge biosynthesis: a novel antistaphylococcal target? Microb Drug Resist 2, 29-41.

McKinney, T. K., Sharma, V. K., Craig, W. A. \& Archer, G. L. (2001). Transcription of the gene mediating methicillin resistance in Staphylococcus aureus (mecA) is corepressed but not coinduced by cognate $m e c A$ and $\beta$-lactamase regulators. J Bacteriol 183, 6862-6868.

Page, R. D. (1996). TREEVIEW: an application to display phylogenetic trees on personal computers. Comput Appl Biosci 12, 357-358.

Phizicky, E. M. \& Fields, S. (1995). Protein-protein interactions: methods for detection and analysis. Microbiol Rev 59, 94-123.

Rain, J. C., Selig, L., De Reuse, H. \& 10 other authors (2001). The protein-protein interaction map of Helicobacter pylori. Nature 409, 211-215.

Rohrer, S. \& Berger-Bächi, B. (2003). FemABX peptidyl transferases: a link between branched-chain cell wall peptide formation and $\beta$-lactam resistance in Gram-positive cocci. Antimicrob Agents Chemother 47, 837-846.

Thompson, J. D., Higgins, D. G. \& Gibson, T. J. (1994). CLUSTAL W: improving the sensitivity of progressive multiple sequence alignment through sequence weighting, position-specific gap penalties and weight matrix choice. Nucleic Acids Res 22, 4673-4680.

Thumm, G. \& Götz, F. (1997). Studies on prolysostaphin processing and characterization of the lysostaphin immunity factor (Lif) of Staphylococcus simulans biovar staphylolyticus. Mol Microbiol 23, 1251-1265.

Weber, B., Ehlert, K., Diehl, A., Reichmann, P., Labischinski, H. \& Hakenbeck, R. (2000). The fib locus in Streptococcus pneumoniae is required for peptidoglycan crosslinking and PBP-mediated $\beta$-lactam resistance. FEMS Mircrobiol Lett 188, 81-85.

Yan, K., Pearce, K. H. \& Payne, D. J. (2000). A conserved residue at the extreme C-terminus of FtsZ is critical for the FtsA-FtsZ interaction in Staphylococcus aureus. Biochem Biophys Res Commun 270, 387-392.

Yan, K., Sossong, T. M. \& Payne, D. J. (2001). Regions of FtsZ important for self-interaction in Staphylococcus aureus. Biochem Biophys Res Commun 284, 515-518. 